\title{
The Role of the RNA-Binding Protein Family MEX-3 in Tumorigenesis
}

\author{
Simon Jasinski-Bergner, André Steven and Barbara Seliger * \\ Institute for Medical Immunology, Martin Luther University Halle-Wittenberg, 06112 Halle (Saale), Germany; \\ simon.jasinski@uk-halle.de (S.J.-B.); andre.steven@uk-halle.de (A.S.) \\ * Correspondence: barbara.seliger@uk-halle.de; Tel.: +49-345-557-1357; Fax: +49-345-557-4055
}

Received: 2 July 2020; Accepted: 21 July 2020; Published: 23 July 2020

\begin{abstract}
The muscle excess 3 (MEX-3) protein was first identified in Caenorhabditis elegans (C. elegans), and its respective homologues were also observed in vertebrates, including humans. It is a RNA-binding protein (RBP) with an additional ubiquitin E3 ligase function, which further acts as a post-transcriptional repressor through unknown mechanisms. In humans, MEX-3 proteins post-transcriptionally regulate a number of biological processes, including tumor immunological relevant ones. These have been shown to be involved in various diseases, including tumor diseases of distinct origins. This review provides information on the expression and function of the human MEX-3 family in healthy tissues, as well after malignant transformation. Indeed, the MEX-3 expression was shown to be deregulated in several cancers and to affect tumor biological functions, including apoptosis regulation, antigen processing, and presentation, thereby, contributing to the immune evasion of tumor cells. Furthermore, current research suggests MEX-3 proteins as putative markers for prognosis and as novel targets for the anti-cancer treatment.
\end{abstract}

Keywords: MEX-3; immune evasion; HLA class I; antigen presentation; antigen processing; cancer

\section{Introduction}

RNA-binding proteins (RBPs) play a critical role in the regulation of various RNA processes. After binding to their target RNA molecules, they form ribonucleoprotein complexes to regulate important processes, including splicing, cleavage, and polyadenylation, transport, translation, and degradation of coding and even different non-coding RNA species, such as long non-coding RNAs (lnRNAs) and microRNAs (miRNAs), as well as their precursors. It is estimated that mammalian cells harbor $>1000$ RBPs [1].

In general, RBPs contain RNA-binding domains (RBDs) for the binding of a special RNA sequence motif or structural motifs like the RNA recognition motif, heterogeneous ribonucleoprotein (hnRNP) K homology domain $(\mathrm{KH})$, or the DEAD box helicase domain [2-5]. Recently, studies identified a novel class of RBPs lacking canonical RBDs, but containing unorthodox binding sites for RNA interaction [1,2]. Despite many computational methods being reported to predict RBP binding sites by in silico sequence analyses [6], this new group of RBPs circumvents the possibility of in silico prediction for their binding sites in RNA molecules. Furthermore, functional analyses for accurate RBP target validation are still mandatory.

Concerning their activity, RBPs are involved in a broad spectrum of physiological and patho-physiological processes, like autoimmune diseases and cancer. Thus far, numerous RBPs have been described, which are involved in the initiation and progression of tumors [2,7]. These include, among others, the evolutionally conserved RBP family MEX-3 (muscle excess 3), consisting of four members (MEX-3A-D). All four MEX-3 proteins contain two RNA-binding KH domains and an ubiquitin E3 ligase RING domain [8], suggesting that E3 ligases not only affect the protein fate, 
but also the RNA decay, through mechanisms that are unknown, thus far [9]. Members of the human MEX-3 family are not only involved in homeostasis and balance between cell self-renewal and differentiation, but also in the processes of malignant transformation. MEX-3A and MEX-3C proteins were recently reported to act as negative post-translational regulators of several target genes. They mediate ubiquitination, leading to a proteasome-dependent degradation of their target proteins, also including cancer-relevant target proteins like the tumor suppressor RIG-I, which could be ubiquitinated by MEX-3A, during glioblastoma tumorigenesis [10]. Interestingly, the ubiquitination of the RIG-I protein was also reported for the MEX-3C protein [11]. Next to this, the MEX-3 proteins also exert an additional and so far not completely understood mechanism of target mRNA ubiquitination, which causes mRNA decay, affecting the post-transcriptional gene regulation of several target genes, including HLA class I genes [12]. Dependent on the tumor type and family member, MEX-3 expression correlates with an increased or reduced patients' survival. This review summarizes the expression and role of human MEX-3 proteins in tumorigenesis, as well as its potential as a putative target for anti-cancer therapy.

\section{History of MEX-3}

MEX-3 is a RNA-binding translational repressor first discovered in nematode C. elegans, with a role in the embryonic and post-embryonic development. It contains two tandem repeat KH domains characterized as a conserved region interacting with the $3^{\prime}$ untranslated region (UTR) of its target PAL-1 and inhibits its translation [13].

In 2006, Andrew Fire and Craig Mellow earned the Nobel Prize in Medicine and Physiology for the discovery of RNA interference, using e.g., RNA interference against MEX-3 mRNA through transfection of its anti-sense RNA into C. elegans embryos. In the case of a complete MEX-3 mRNA knockdown, an embryonic arrest was observed [14].

Mutations in the MEX-3 gene disrupting its expression are lethal. MEX-3 is involved in cell fate specification in the early embryonic stage and contributes to the maintenance of the totipotency of the germ line in adult worms. In C. elegans, it represents a fundamental regulator of asymmetry, mediating the early steps of cell fate determination [13]. In adult C. elegans, MEX-3 is involved in the maintenance of germ stem cells [15]. Despite an extensive existing knowledge of MEX-3 in C. elegans, the function of MEX-3 family members in vertebrates are not well characterized.

\section{Characteristic Features of Human MEX-3 Family Members}

Human MEX-3 represents a family of evolutionarily highly conserved RBPs. The human MEX-3 proteins belong to the heterogeneous nuclear ribonucleoprotein (hnRNP) family of RBPs. They share a high homology with the C. elegans MEX-3. In human and murine genomes, four MEX-3 homologous proteins, named MEX-3A, $-3 B,-3 C$, and $-3 D$, were identified [8], which share a high homology to MEX-3 of other vertebrates. These four murine MEX-3 proteins are approximately $95 \%$ identical at the amino acid level to the human counterparts [8]. The MEX-3A-D proteins consist of two KH RNA-binding domains at the $\mathrm{N}$-terminus, a zinc finger (ZNF) domain, which mediates the protein interactions at the C-terminus and an ubiquitin E3 ligase RING domain, which is absent in the MEX-3 protein of C. elegans [8]. The human MEX-3 genes are located on different chromosomes-MEX-3A is encoded on chromosome 1q22, MEX-3B on chromosome 15q25.2, MEX-3C on chromosome 18q21.2, and MEX-3D on chromosome 19p13.3. Interestingly, the chromosomal region 19p13.3 was classified as a fragile chromosomal region, frequently deleted in various human cancers [16]. In colorectal cancer, $M E X-3 C$ was identified as a cancer chromosome instability gene, which is frequently lost in CIN ${ }^{+}$tumors [17].

Human MEX-3 family members are differentially expressed in healthy tissues of distinct origins, which is summarized in Figure 1. The tissues exerting high MEX-3 protein levels are the male testis (MEX-3B) and the placenta (MEX-3D), which represent immune-privileged tissues avoiding inflammatory reactions through downregulation of classical human leukocyte antigen (HLA) class Ia molecules and upregulation of anti-inflammatory molecules like IL-10 and TGF- $\beta$, as well as 
non-classical HLA class Ib molecules, like HLA-G and HLA-E, respectively. These immune-privileged tissues include the male testis, but also the placenta protecting the developing fetus with its paternal antigens from the maternal immune system, also in the brain and the cornea (Figure 1A) (originally defined as tissues in which foreign tissue grafts can survive for an extended time) $[18,19]$. Unfortunately, no expression data for the MEX-3A protein are currently available.

\section{A}

protein levels in healthy human tissues by The Human Protein Atlas

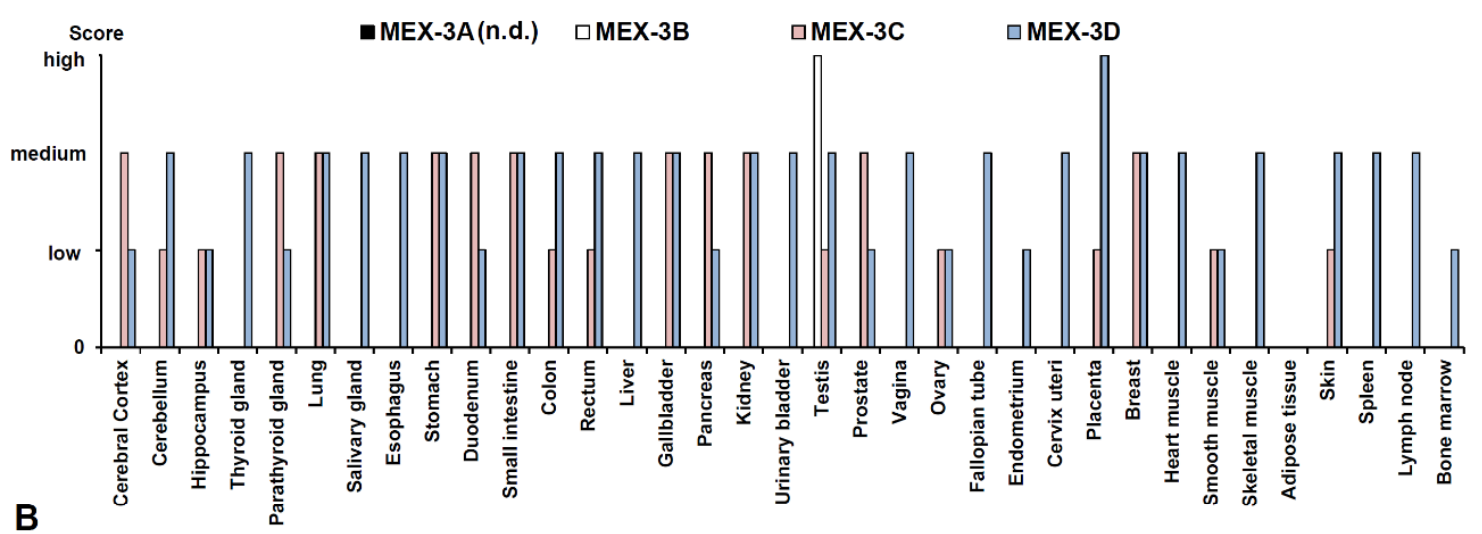

normalized transcript data in healthy human tissues by The Human Protein Atlas

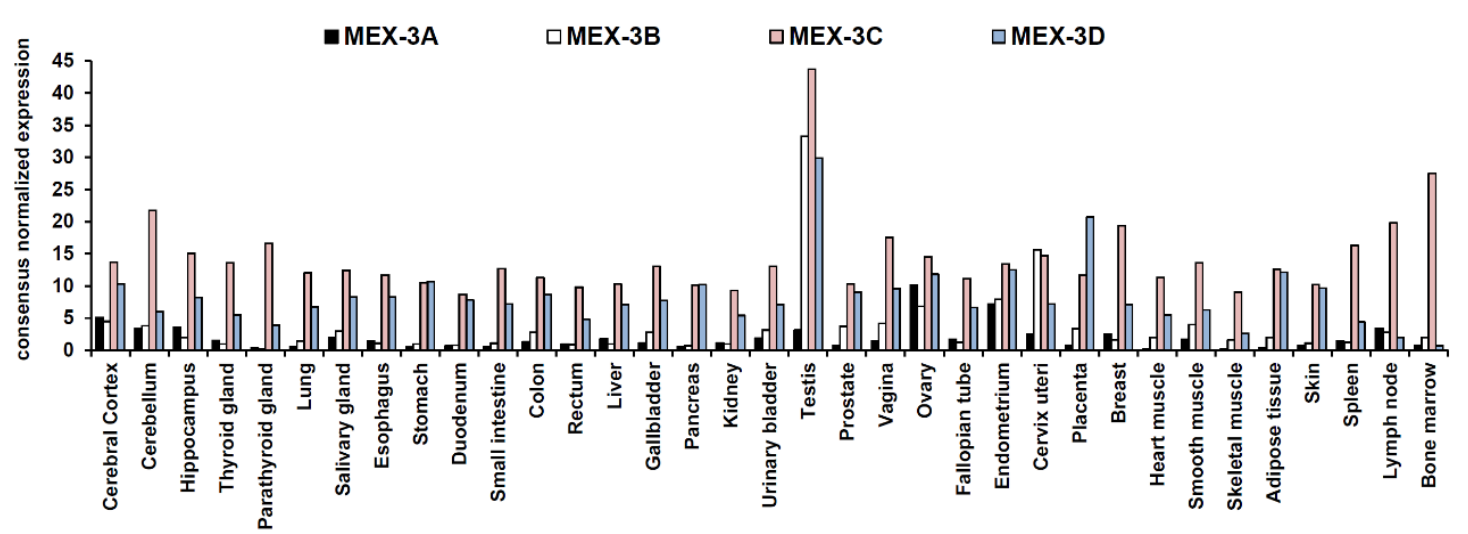

Figure 1. Protein and mRNA levels of MEX-3A-D in healthy human tissues of distinct origin. The protein (A) and mRNA (B) levels of the MEX-3A-D in selected healthy human tissues are expressed as bar diagrams based upon the data sets of The Human Protein Atlas [20-22]. Protein data for MEX-3A were not available. The protein levels were scored using immunohistochemistry data and the mRNA data are expressed as consensus normalized expression levels created by combining the data from the three transcriptomics datasets (HPA, GTEx, and FANTOM5) using an internal normalization.

MEX-3A, MEX-3B, and MEX-3C mRNA expression was found in the fetal brain, thymus, and testis and in general high MEX-3D mRNA levels were reported in a study also investigating a limited number of other human tissue specimens [8]. There exists conflicting data using TCGA data (Figure 1B), in particular regarding MEX-3D, which is expressed at low levels in lymphoid tissues. In contrast to the MEX-3D mRNA, data from lymphoid tissues were derived from the total RNA panel (BD Biosciences), reported by Buchet-Poyau et al. 2007 [8]. The other MEX-3 proteins are heterogeneously expressed in different tissues. This might reflect their distinct physiological function, which appears to be comparable to that of MEX-3 of C. elegans. In addition to testis and placenta, the immune-privileged cerebrum, cerebellum, and ovaries also exhibit higher levels of MEX-3 mRNA. Furthermore, the MEX-3C mRNA can be detected at high levels in primary and secondary lymphoid tissues, in particular in the bone 
marrow, spleen, and lymph nodes (Figure 1B). Very high levels of MEX-3B, -3C, and -3D mRNA were found in normal testicular tissues.

It is noteworthy that the expression levels of MEX-3 mRNA and proteins do not correlate in all tissues. Transcripts can often be detected with higher frequencies than the corresponding proteins, suggesting that the MEX-3 gene products underlay post-transcriptional or post-translational gene regulation. Such post-transcriptional control might include the regulation by microRNAs (miRs). Indeed, MEX-3C mRNA is targeted by miR-451a [23], although other RBPs might contribute to the stability of the MEX-3 mRNAs. It is even possible that the MEX-3 proteins regulate the mRNA and protein stability of themselves through ubiquitination.

MEX-3 family members predominantly accumulate in the cytoplasm, but can shuttle between the cytoplasm and nucleus. The main molecular characteristics and function of the MEX-3 proteins are summarized in Table 1.

Table 1. Main molecular and cellular characteristics of the MEX-3 homologs in the context of cancer.

\begin{tabular}{|c|c|c|}
\hline MEX-3 Homolog & Main Characterization & Reference \\
\hline \multirow{6}{*}{ MEX-3A } & enhanced cell proliferation and inhibition of apoptosis in bladder cancer & [24] \\
\hline & $\begin{array}{l}\text { enhanced cell proliferation, anchorage-independent growth and migration } \\
\text { in gastric cancer }\end{array}$ & [25] \\
\hline & $\begin{array}{l}\text { higher expression in papillary type bladder urothelial cancer, but no effect } \\
\text { on prognosis }\end{array}$ & [26] \\
\hline & presence of a nuclear export sequence, connected to colorectal cancer & [27] \\
\hline & stemness-related gene, upregulation by calcitriol in tumor organoids & [28] \\
\hline & $\begin{array}{l}\text { regulator of post-transcriptional and post-translational control by } \\
\text { ubiquitination of target mRNAs/proteins like CDX2 mRNA and the } \\
\text { RIG-I protein }\end{array}$ & {$[10,29]$} \\
\hline \multirow{7}{*}{ MEX-3B } & induction of apoptosis by miR-92a targeting Bim & [30] \\
\hline & inhibition miR-487b-3p and upregulation of IL-33 & [31] \\
\hline & upregulation of CXCL2, induction of neutrophil chemotaxis and migration & [32] \\
\hline & regulation of Rap1 pathway & [33] \\
\hline & ubiquitination of Runx3 and increase invasion of gastric cancer cells & [34] \\
\hline & downregulation of HLA-A expression & [35] \\
\hline & post-transcriptional regulator of HLA-A & [36] \\
\hline \multirow{8}{*}{ MEX-3C } & suppression of cancer chromosomal instability & [17] \\
\hline & targeted by miR-451a in colorectal cancer after radio therapy & [23] \\
\hline & regulation of lipid metabolism through JNK pathway in bladder cancer & [37] \\
\hline & downregulation in pregnancy-associated breast cancer & [38] \\
\hline & degradation of MHC I mRNA by ubiquitination & {$[9]$} \\
\hline & activation of NK cells increases MEX-3C levels & [39] \\
\hline & binding to the MRE10 motif CAGAGUUUAG & [40] \\
\hline & $\begin{array}{l}\text { regulator of post-transcriptional and post-translational control by } \\
\text { ubiquitination of target mRNAs/proteins like MHC class I mRNA and the } \\
\text { RIG-I protein }\end{array}$ & {$[11,12]$} \\
\hline \multirow{2}{*}{ MEX-3D } & modulation by chemotherapy in AML & [41] \\
\hline & overexpression in androgen-independent prostate cancer & [42] \\
\hline
\end{tabular}

Actual studies report a contribution of human MEX-3 proteins in the regulation of mRNA decay and post-transcriptional control of target genes involved in different physiological processes, including 
hypertension [43], post-natal growth [44], as well as tumor biology relevant processes, like energy metabolism, apoptosis, and immune responses [9,12,17]. For example, MEX-3C (also known as RKHD2) is an E3 ubiquitin ligase, which plays a role in apoptosis, translational repression, chromosomal instability, energy, homeostasis, obesity, and post-natal growth [17,40,44-47]. MEX-3D exerts an inverse expression with the anti-apoptotic BCL2 protein in induced-neuronal cells derived from human fibroblasts through an undefined mechanism [48]. In addition, MEX-3A and -B act as components of RNA granules called P bodies [49] and are associated with Argonaute (AGO) proteins as key components of the RNA-induced silencing complex and were demonstrated to be involved in the development of tumors.

\section{MEX-3 and Tumorigenesis}

Recently, RBPs are of growing interest for their ability (i) to play a role in neoplastic transformation and oncogenesis, thereby, affecting the stabilization of tumor-relevant target mRNAs or (ii) to regulate transcription factors that control these tumor-relevant genes. In addition, RBPs might be involved in alternative splicing processes, which are also altered upon malignant transformation [50].

The role of human MEX-3 proteins in tumorigenesis still needs to be defined in much greater detail. In many tumor tissues, MEX-3 homologs are overexpressed when compared to corresponding normal tissues, with some exceptions. As shown in Figure 2, the MEX-3 family members are heterogeneously expressed in the various tumors types, as visualized by the human protein atlas [20-22]. While MEX-3A-C showed high expression levels in testicular, endometrial, breast, ovarian, and brain cancer, MEX-3D showed no tumor-type specific increased expression levels. In addition to such TCGA data, a study reported higher expression levels of MEX-3A mRNA levels in human gastric cancer tissues, compared to matched, adjacent, non-cancer tissues, suggesting that human MEX-3A is involved in the development and metastasis formation of this disease [25]. Furthermore, increased MEX-3A levels are also reported in liver cancer, which were significantly associated with a poor patients' survival [51].

Concerning the functional relevance of MEX-3A expression, its downregulation in gastric cancer cell lines caused a reduced cell proliferation, migration, and transformation capacity. These data suggest that MEX-3A plays a role in the initiation and progression of gastric or liver cancer and might also represent a novel promising therapeutic target for both malignancies [25].

Another study reports that MEX-3C is highly expressed in bladder cancer, but was not detectable in healthy control tissues by immunohistochemistry. This aberrant MEX-3C expression in the bladder cancer, correlated with clinical features, in particular with patients' prognosis [37]. Furthermore, overexpression of MEX-3C in vitro promotes intracellular adhesion, invasion, and migration. This is associated with an activated JNK signaling by upregulating the downstream protein levels of fatty acid synthase (FASN), the acetyl-CoA-carboxylase-1 (ACC1), and the sterile regulatory element binding protein-1 (SREBP1) [37]. MEX-3C mRNA is targeted by the tumor suppressive miR-451a, which inhibits metastasis formation, as well as proliferation by regulating the epithelial mesenchymal transition (EMT) [52].

The E3 ligase MEX-3B was shown to be involved in the ubiquitination of the runt-related transcription factor 3 (RUNX3), leading to its degradation in gastric cancers [34]. MEX-3B is an important cellular target for the design of epigenetic therapies for chronic hepatitis B virus (HBV) infection, and is associated with a poor prognosis of HBV-associated liver cancer [53]. In addition, MEX-3B could modulate stress-induced apoptosis through post-transcriptional gene regulation of the pro-apoptotic BIM gene, which is induced by MYC and leads to apoptosis by activation of BAX/BAK. This is mediated by the binding of MEX-3B to the $3^{\prime}$ untranslated region (UTR) of BIM, which impairs the interaction with the Ago-miR-92a complex [30,54].

Regarding the underlying mechanisms, through which the MEX-3 proteins are able to induce or contribute to malignant transformation, MEX-3 proteins were shown to ubiquitinate target mRNAs 
and proteins, marking them to decay. For example, MEX-3A and MEX-3C ubiquitinate the tumor suppressor RIG-I, which affects tumorigenesis in glioblastoma [10,11].

A

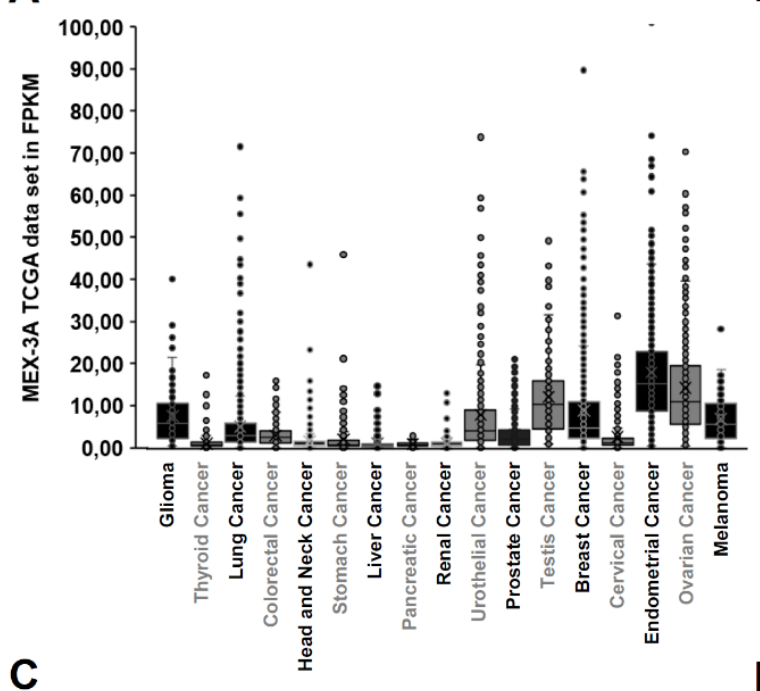

C

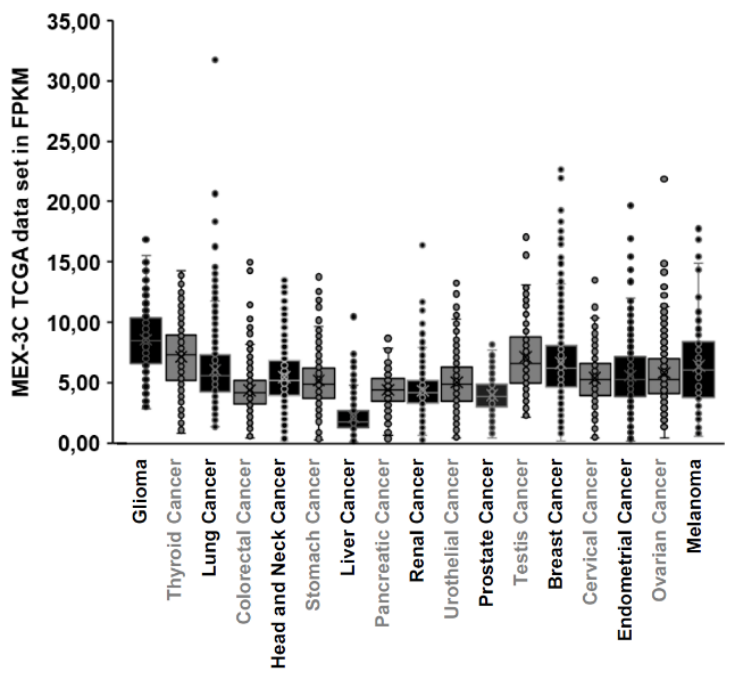

B

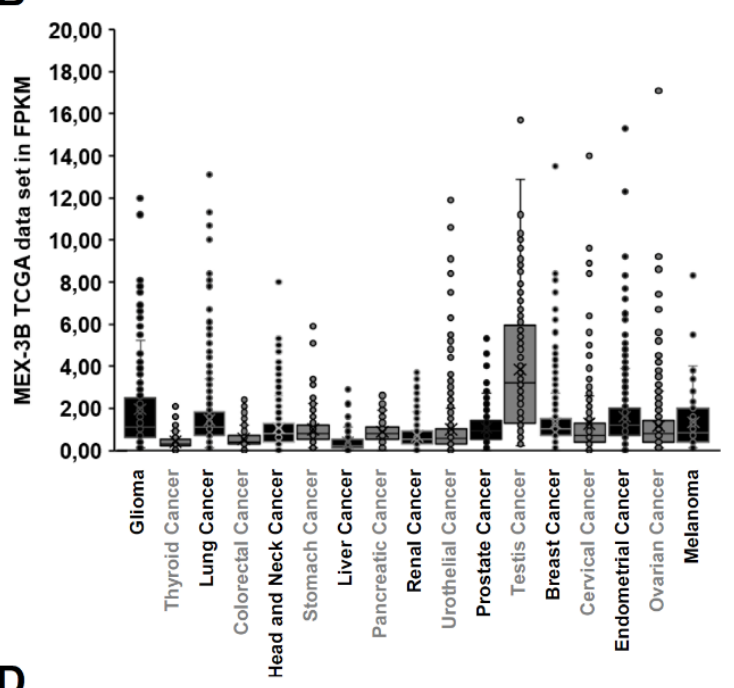

D

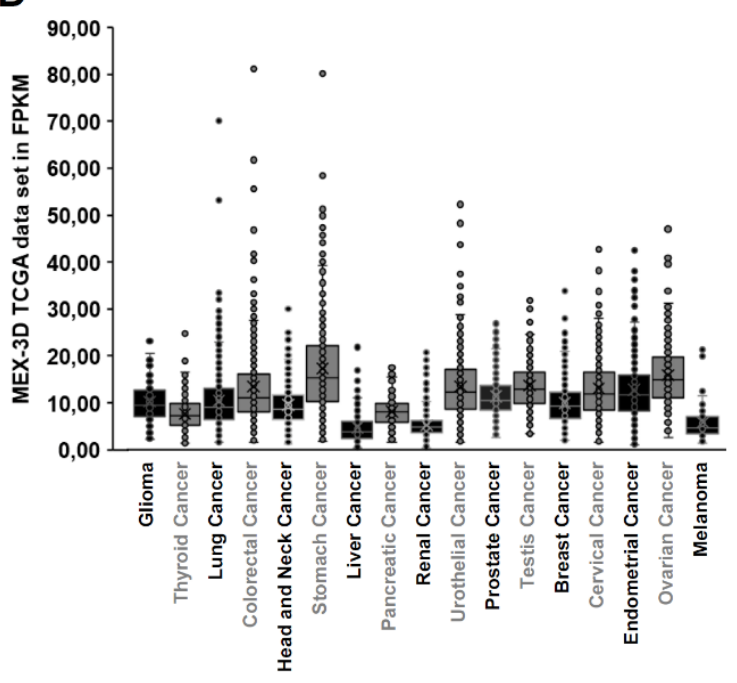

Figure 2. TCGA data sets for MEX-3A-D gene expression in selected human cancers. (A-D): TCGA expression data for MEX-3A-D in 17 different tumor entities expressed as median FPKM (number fragments per kilobase of exon per million reads) generated by The Human Protein Atlas [20-22].

Furthermore, the expression of the MEX-3 family members was associated with disease progression and patients' overall survival (OS), but was dependent on the analyzed tumor types (Table 2). Bioinformatics analysis using the Tumor Cancer Genome Atlas (TCGA) revealed low MEX-3A $(p=0.0026)$ and low MEX-3C mRNA $(p=0.0089)$ expression levels in endometrial cancer (no data for testicular germ cell tumors available), which were significantly associated with a better overall survival (OS). Low MEX-3B mRNA levels were also associated with a better, but not statistically significant OS $(p=0.068)$. In contrast, low MEX-3D mRNA levels were associated with a poorer OS $(p=0.016)$ (Figure 3). Despite some exceptions, these tendencies were also detectable in other tumor entities. 
Table 2. Influence of MEX-3 homologs on the overall survival (OS) of cancer patients.

\begin{tabular}{ccccc}
\hline Cancer & MEX-3A & MEX-3B & MEX-3C & MEX-3D \\
\hline Bladder & 0.333 & 0.858 & 0.667 & 0.016 \\
Breast & 0.852 & 0.399 & 0.305 & high better \\
Cervical & 0.920 & 0.839 & 0.065 & 0.719 \\
Head and Neck & 0.336 & 0.907 & low better & 0.358 \\
Kidney Clear Cell & $7.9 \times 10^{-03}$ & $4.1 \times 10^{-04}$ & 0.757 & 0.416 \\
Kidney Papillary & low better & low better & 0.565 & 0.141 \\
& 0.415 & 0.037 & 0.081 & 0.036 \\
Liver & $5.0 \times 10^{-03}$ & low better & low better & low better \\
Lung & high better & 0.626 & 0.017 & 0.831 \\
Skin & 0.072 & 0.943 & low better & 0.033 \\
& high better & & 0.177 & low better \\
\hline
\end{tabular}

Blue numbers indicate a better patients' OS with higher expression levels of the MEX-3 homologs in the indicated tumor entity, while the red highlighted numbers represent the correlation of a better OS with lower MEX-3 gene expression levels. Survival data were analyzed with the R2 database (https://hgserver1.amc.nl/), using the appropriate TCGA datasets. The numbers reflect the statistical significance between the OS and the expression levels of the MEX-3 genes with a $p$-value of $<0.1$ used as the significance threshold.

A
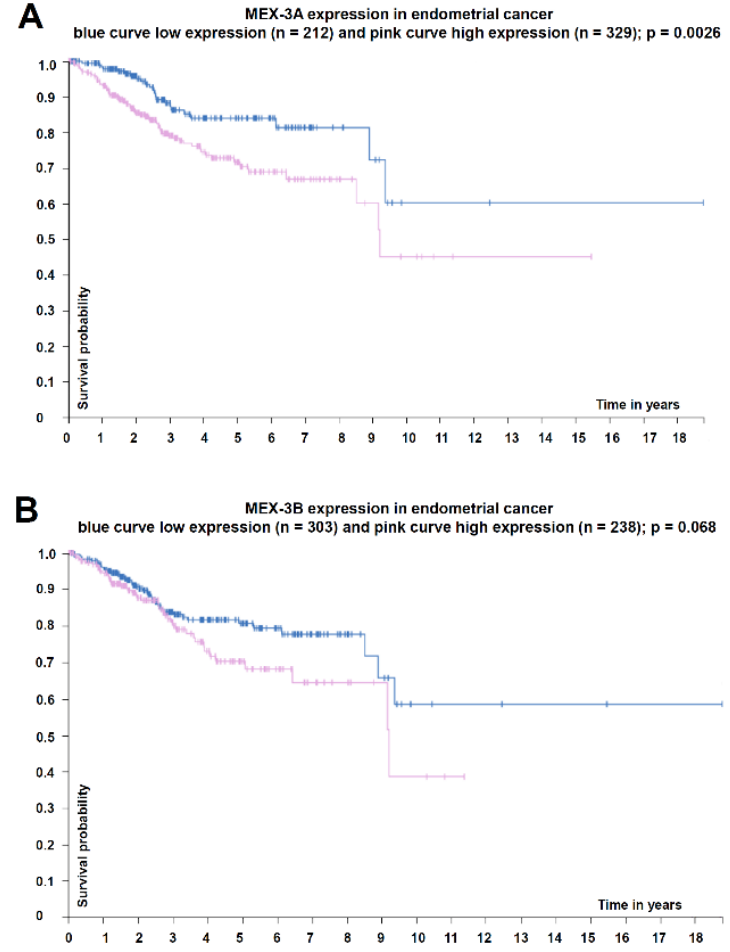

C

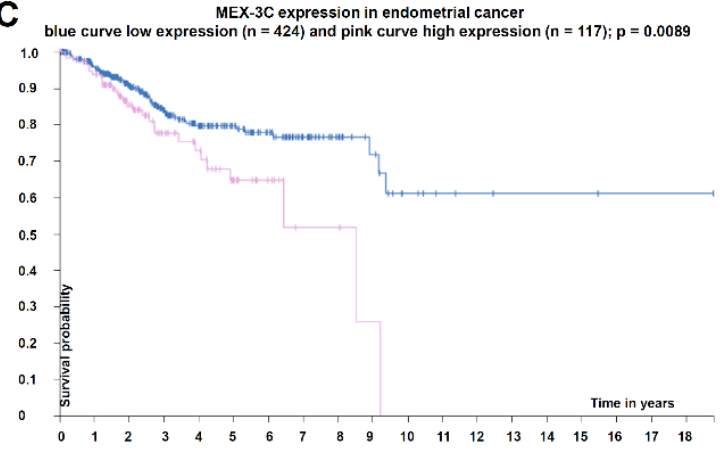

D

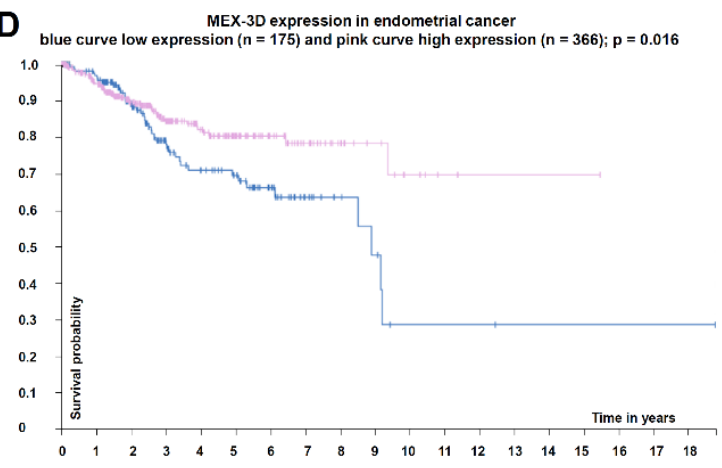

Figure 3. Correlation of the overall survival of endometrial cancer patients' with MEX-3A-D expression. (A-D): Kaplan Meier curves for the overall survival of cancer endometrial patients were generated and correlated to the MEX-3A-D expression levels using The Human Protein Atlas [20-22].

It is noteworthy that the observed TCGA data are based on mRNA expression levels, which under consideration of a putative post-transcriptional or post-translational gene regulation might not reflect the in vivo protein-based results. 


\section{MEX-3 and Immune Responses}

The classical HLA-Ia expression is essential for cell survival, immune response, and other physiological activities. Foreign antigens, such as viral and tumor antigens presented by HLA-Ia molecules on the cell surface could be recognized by $\mathrm{CD} 8^{+}$cytotoxic $T$ lymphocytes (CTL) leading to the elimination of tumor or virus-infected cells. Downregulation, total, or allele-specific loss of HLA-I are a common features of tumors (analogue also in immune privileged tissues) and facilitate CTL-mediated escape [55]. Recently, a post-transcriptional modification of HLA-I mRNAs through ubiquitination was demonstrated, which provides a potential mechanism for controlling the HLA-I turnover, thereby, interfering with immune responses. Some ubiquitin E3 ligases were shown to encode RNA-binding domains (RBD) and were predicted to bind and regulate mRNA [9]. This mechanism could also control the HLA-I antigens in the endoplasmic reticulum (ER) and at the cell surface, suggesting that HLA-I ubiquitination is involved in the post-translational control of the HLA-I assembly.

MEX-3C was shown to be involved in protein regulation/degradation and ubiquitination. Regarding its expression, MEX-3C could be detected in innate immune cells, in particular in activated NK cells, affecting their cytotoxic activity. Recently, a functional siRNA screen identified MEX-3C as a novel RNA-binding E3 ubiquitin ligase, which is responsible for the post-transcriptional regulation of common HLA-A allotypes, without affecting HLA-B and HLA-C [56]. It is able to bind and induce the degradation of HLA-A2 mRNA by binding to its $3^{\prime}$ UTR. The RING domain of MEX-3C is not required for the downregulation of HLA-A2 surface levels, but for the mRNA degradation of HLA-A2, thereby, suggesting a novel mechanism of HLA-I allotype-specific regulation. These results demonstrate a link between ubiquitination and mRNA decay [9]. Ubiquitin is known to regulate the HLA-I mRNA deadenylation, which is required for HLA-I mRNA degradation. It is noteworthy that neither proteasome nor lysosome inhibitors are able to rescue the MEX-3C-mediated HLA-I mRNA degradation, suggesting a non-proteolytic function for ubiquitin in the regulation of the mRNA decay [12]. In addition, MEX-3B could destabilize its own mRNA by binding to the 3' UTR, which contains elements for mRNA destabilization and translational enhancement.

The function of MEX-3B in immune responses has not yet been well studied, although some analyses demonstrated that MEX-3B can act as a co-receptor of the toll-like receptor 3 involved in the innate anti-viral response [57]. In contrast, the role of MEX-3B in the T cell-mediated anti-tumoral immune responses is not yet analyzed in detail. Interestingly, overexpression of MEX-3B in melanoma cells can downregulate the expression of HLA-A2 by binding to the $3^{\prime}$ UTR of HLA-A, thereby, blocking the recognition and CD8 ${ }^{+}$CTL-mediated killing of tumor cells. This was associated with resistance to immunotherapies [35]. Using melanoma as a model, lower expression of MEX-3B correlated with response to checkpoint blockade, with an antibody directed against the programed cell death 1 (PD-1) receptor, while MEX-3B overexpression inhibited T cell-mediated tumor elimination. These data further suggest that MEX-3 regulates antigen presentation downstream of the interferon (IFN) signaling pathway.

This hypothesis was confirmed by the evaluation of The Cancer Genome Atlas (TCGA) data derived from 150 human testicular germ line tumors, as summarized in Table 3. The expression levels of the $M E X-3 A-D$ genes were correlated to the gene expression pattern of selected genes involved in antigen presentation and processing, immune evasion, and IFN- $\gamma$ signaling. Interestingly, the expression of the $M E X-3 A-D$ genes, in particular of $M E X-3 D$, showed a statistically significant inverse correlation to the expression of antigen presentation and processing components. Furthermore, $M E X-3$ genes were inversely expressed, compared to the two chaperones calnexin and calreticulin, which are important for the assembly of the HLA-I complex within the ER [58]. This was in contrast to the positive trend of correlated expression of the MEX-3 genes and the components of the IFN- $\gamma$ signaling pathway. 
Table 3. Correlation of the MEX-3A-D expression to the expression of selected immune modulatory genes.

\begin{tabular}{|c|c|c|c|c|}
\hline $\begin{array}{l}\text { Correlated } \\
\text { Expression }\end{array}$ & MEX-3A & MEX-3B & MEX-3C & MEX-3D \\
\hline HLA-A & $\begin{array}{c}R=-0.257 \\
p=1.48 \times 10^{-03}\end{array}$ & $\begin{array}{c}R=-0.111 \\
p=0.176\end{array}$ & $\begin{array}{c}R=-0.294 \\
p=2.59 \times 10^{-04}\end{array}$ & $\begin{array}{c}R=-0.447 \\
p=9.97 \times 10^{-09}\end{array}$ \\
\hline HLA-B & $\begin{array}{c}R=-0.175 \\
p=0.032\end{array}$ & $\begin{array}{c}R=-0.045 \\
p=0.583\end{array}$ & $\begin{array}{c}R=-0.174 \\
p=0.034\end{array}$ & $\begin{array}{c}R=-0.372 \\
p=2.77 \times 10^{-06}\end{array}$ \\
\hline HLA-C & $\begin{array}{c}R=-0.284 \\
p=4.32 \times 10^{-04}\end{array}$ & $\begin{array}{c}R=-0.126 \\
p=0.125\end{array}$ & $\begin{array}{c}R=-0.254 \\
p=1.70 \times 10^{-03}\end{array}$ & $\begin{array}{c}R=-0.288 \\
p=3.60 \times 10^{-04}\end{array}$ \\
\hline B2M & $\begin{array}{c}R=-0.135 \\
p=0.099\end{array}$ & $\begin{array}{l}R=0.061 \\
p=0.456\end{array}$ & $\begin{array}{c}R=-0.102 \\
p=0.213\end{array}$ & $\begin{array}{c}R=-0.385 \\
p=1.17 \times 10^{-06}\end{array}$ \\
\hline TAP1 & $\begin{array}{c}R=-0.161 \\
p=0.050\end{array}$ & $\begin{array}{l}R=0.019 \\
p=0.819\end{array}$ & $\begin{array}{c}R=-0.039 \\
p=0.635\end{array}$ & $\begin{array}{c}R=-0.376 \\
p=2.14 \times 10^{-06}\end{array}$ \\
\hline TAP2 & $\begin{array}{c}R=-0.167 \\
p=0.041\end{array}$ & $\begin{array}{l}R=0.046 \\
p=0.579\end{array}$ & $\begin{array}{c}R=-0.013 \\
p=0.877\end{array}$ & $\begin{array}{c}R=-0.339 \\
p=2.15 \times 10^{-05}\end{array}$ \\
\hline TPN & $\begin{array}{c}R=-0.134 \\
p=0.103\end{array}$ & $\begin{array}{c}R=-0.032 \\
p=0.699\end{array}$ & $\begin{array}{c}R=-0.293 \\
p=2.76 \times 10^{-04}\end{array}$ & $\begin{array}{c}R=-0.457 \\
p=4.02 \times 10^{-09}\end{array}$ \\
\hline CALR & $\begin{array}{c}R=-0.329 \\
p=3.95 \times 10^{-05}\end{array}$ & $\begin{array}{c}R=-0.520 \\
p=8.70 \times 10^{-12}\end{array}$ & $\begin{array}{c}R=-0.458 \\
p=3.67 \times 10^{-09}\end{array}$ & $\begin{array}{l}R=0.075 \\
p=0.362\end{array}$ \\
\hline CANX & $\begin{array}{c}R=-0.526 \\
p=4.65 \times 10^{-12}\end{array}$ & $\begin{array}{c}R=-0.483 \\
p=3.99 \times 10^{-10}\end{array}$ & $\begin{array}{c}R=-0.133 \\
p=0.105\end{array}$ & $\begin{array}{c}R=-0.182 \\
p=0.026\end{array}$ \\
\hline ERP57 & $\begin{array}{c}R=-0.069 \\
p=0.404\end{array}$ & $\begin{array}{c}R=-0.036 \\
p=0.661\end{array}$ & $\begin{array}{l}R=0.015 \\
p=0.858\end{array}$ & $\begin{array}{c}R=-0.155 \\
p=0.058\end{array}$ \\
\hline ERAP1 & $\begin{array}{c}R=-0.114 \\
p=0.165\end{array}$ & $\begin{array}{l}R=0.034 \\
p=0.681\end{array}$ & $\begin{array}{c}R=-0.132 \\
p=0.107\end{array}$ & $\begin{array}{c}R=-0.133 \\
p=0.104\end{array}$ \\
\hline ERAP2 & $\begin{array}{c}R=-0.010 \\
p=0.907\end{array}$ & $\begin{array}{c}R=-0.023 \\
p=0.779\end{array}$ & $\begin{array}{c}R=-0.126 \\
p=0.123\end{array}$ & $\begin{array}{c}R=-0.295 \\
p=2.52 \times 10^{-04}\end{array}$ \\
\hline LMP2 & $\begin{array}{c}R=-0.150 \\
p=0.068\end{array}$ & $\begin{array}{c}R=-0.036 \\
p=0.661\end{array}$ & $\begin{array}{c}R=-0.159 \\
p=0.053\end{array}$ & $\begin{array}{c}R=-0.412 \\
p=1.68 \times 10^{-07}\end{array}$ \\
\hline LMP7 & $\begin{array}{c}R=-0.162 \\
p=0.048\end{array}$ & $\begin{array}{c}R=-0.022 \\
p=0.788\end{array}$ & $\begin{array}{c}R=-0.255 \\
p=1.64 \times 10^{-03}\end{array}$ & $\begin{array}{c}R=-0.398 \\
p=4.55 \times 10^{-07}\end{array}$ \\
\hline LMP10 & $\begin{array}{c}R=-0.201 \\
p=0.014\end{array}$ & $\begin{array}{c}R=-0.161 \\
p=0.049\end{array}$ & $\begin{array}{c}R=-0.340 \\
p=2.02 \times 10^{-05}\end{array}$ & $\begin{array}{c}R=-0.521 \\
p=8.59 \times 10^{-12}\end{array}$ \\
\hline PDL1 & $\begin{array}{c}R=-0.077 \\
p=0.347\end{array}$ & $\begin{array}{l}R=0.060 \\
p=0.469\end{array}$ & $\begin{array}{c}R=0.302 \\
p=1.72 \times 10^{-04}\end{array}$ & $\begin{array}{c}R=-0.301 \\
p=1.80 \times 10^{-04}\end{array}$ \\
\hline HLA-E & $\begin{array}{c}R=-0.236 \\
p=3.61 \times 10^{-03}\end{array}$ & $\begin{array}{c}R=-0.004 \\
p=0.963\end{array}$ & $\begin{array}{c}R=-0.089 \\
p=0.280\end{array}$ & $\begin{array}{c}R=-0.329 \\
p=3.94 \times 10^{-05}\end{array}$ \\
\hline HLA-G & $\begin{array}{c}R=-0.410 \\
p=1.89 \times 10^{-07}\end{array}$ & $\begin{array}{c}R=-0.176 \\
p=0.032\end{array}$ & $\begin{array}{c}R=-0.168 \\
p=0.040\end{array}$ & $\begin{array}{c}R=-0.210 \\
p=9.92 \times 10^{-03}\end{array}$ \\
\hline IFNG & $\begin{array}{c}R=-0.087 \\
p=0.291\end{array}$ & $\begin{array}{l}R=0.015 \\
p=0.859\end{array}$ & $\begin{array}{l}R=0.160 \\
p=0.050\end{array}$ & $\begin{array}{c}R=-0.249 \\
p=2.08 \times 10^{-03}\end{array}$ \\
\hline IFNGR1 & $\begin{array}{c}R=-0.035 \\
p=0.674\end{array}$ & $\begin{array}{l}R=0.135 \\
p=0.099\end{array}$ & $\begin{array}{c}R=-0.038 \\
p=0.641\end{array}$ & $\begin{array}{c}R=-0.478 \\
p=6.38 \times 10^{-10}\end{array}$ \\
\hline IFNGR2 & $\begin{array}{l}R=0.054 \\
p=0.515\end{array}$ & $\begin{array}{c}R=-0.054 \\
p=0.514\end{array}$ & $\begin{array}{c}R=-0.430 \\
p=3.95 \times 10^{-08}\end{array}$ & $\begin{array}{c}R=-0.178 \\
p=0.029\end{array}$ \\
\hline JAK1 & $\begin{array}{l}R=0.204 \\
p=0.012\end{array}$ & $\begin{array}{c}R=0.517 \\
p=1.24 \times 10^{-11}\end{array}$ & $\begin{array}{c}R=0.288 \\
p=3.46 \times 10^{-04}\end{array}$ & $\begin{array}{c}R=-0.138 \\
p=0.093\end{array}$ \\
\hline JAK2 & $\begin{array}{l}R=0.145 \\
p=0.076\end{array}$ & $\begin{array}{c}R=0.398 \\
p=4.56 \times 10^{-07}\end{array}$ & $\begin{array}{c}R=0.266 \\
p=9.85 \times 10^{-04}\end{array}$ & $\begin{array}{c}R=-0.296 \\
p=2.31 \times 10^{-04}\end{array}$ \\
\hline STAT1 & $\begin{array}{l}R=0.116 \\
p=0.158\end{array}$ & $\begin{array}{c}R=0.219 \\
p=7.00 \times 10^{-03}\end{array}$ & $\begin{array}{c}R=0.266 \\
p=1.01 \times 10^{-03}\end{array}$ & $\begin{array}{c}R=-0.204 \\
p=0.012\end{array}$ \\
\hline IRF1 & $\begin{array}{c}R=-0.171 \\
p=0.036\end{array}$ & $\begin{array}{l}R=0.046 \\
p=0.580\end{array}$ & $\begin{array}{c}R=-0.047 \\
p=0.566\end{array}$ & $\begin{array}{c}R=-0.438 \\
p=2.13 \times 10^{-08}\end{array}$ \\
\hline
\end{tabular}

Based on TCGA data sets of 150 testicular germ cell tumors, the expression data of the MEX-3 mRNAs were correlated to the expression of HLA-Ia und - Ib, APM components, PDL1, and the molecules involved in the IFN- $\gamma$ signaling pathway (http://r2.amc.nl; transform_2log, plotted into Y-Y-plot; p value is significance of correlation). Statistically significant inverse correlated genes are highlighted in red, statistically significant positive correlated genes in blue. (For a better estimation-the very strong correlation of IFN- $\gamma$ and one of its directly induced target genes ICAM1 is $R=0.601$ and $p=4.07 \times 10^{-16}$.). 
In the literature, it was already reported that MEX-3B expression leads to a downregulation of HLA-A, thereby inhibiting cancer immunotherapy of anti-PD-1-treated melanoma patients [35]. In melanoma, different immune evasion strategies were reported, which under physiological conditions contribute to the functional immune-privileged tissue microenvironment, including the downregulation of HLA-Ia surface levels, reduced expression of antigen processing machinery (APM) components, as well as induced expression or secretion of immunomodulatory ligands like HLA-G, HLA-E, PD-L1, TGF- $\beta$, and IL-10 [58-61].

The underlying mechanisms of the negative post-transcriptional control of the MEX-3 proteins to HLA molecules or APM components need to be studied in more detail. First evidences demonstrated a direct inhibitory interaction of the MEX-3B protein to the 3' UTR of the HLA-A mRNA [35]. A similar mechanism was described for MEX3-C downregulating the HLA-A2 mRNA by binding to its $3^{\prime}$ UTR and mRNA ubiquitination [9]. Such interactions might also occur with other MEX-3 proteins and the mRNAs of the APM components, which were statistically significantly inversely correlated, as demonstrated in Table 3.

It was further hypothesized by the authors that these cellular mechanisms, in combination with already known processes like the promoter methylation of HLA genes [62] and altered expression pattern of regulatory microRNAs [63], might contribute to the physiological low surface levels of HLA class Ia molecules in immune-privileged tissues, as well as to pathophysiological levels in solid and hematopoietic malignancies. Furthermore, enhanced MEX-3 protein expression levels were reported after malignant transformation including gonadal cancers, suggesting that MEX-3 contributes to the tumor immune evasion, by directly targeting HLA-I and APM component encoding gene products, as summarized in Figure 4. To sum up, MEX-3 family members are involved in tumorigenesis and affect immune responses, suggesting their use as potential targets for immunotherapy.

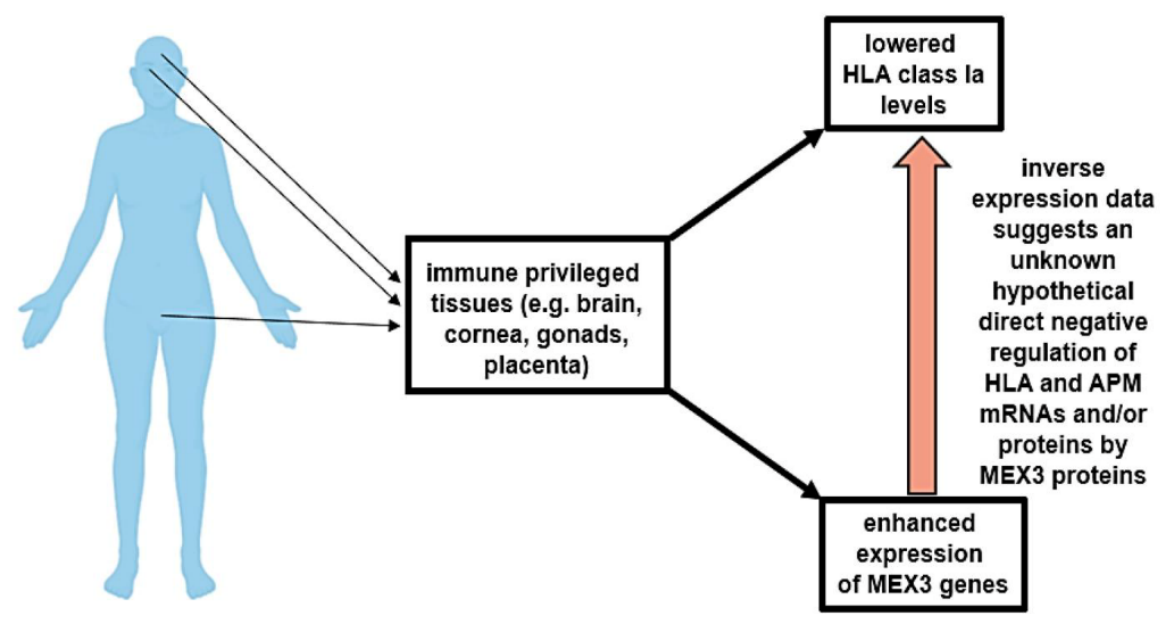

Figure 4. Postulated role of MEX-3 genes in the regulation of HLA class I expression.

To identify more MEX-3 targeted mRNAs, which might get ubiquitinated or degradedan immunoprecipiation using MEX-3 specific antibodies in combination with a prior cross-linking could be performed. Furthermore, other issues of MEX-3 activity and function should be addressed. Do MEX-3 proteins exert different affinities for target proteins and for target mRNAs as an acceptor of ubiquitination? Are such differences equal for all of the four MEX-3 proteins? Is mRNA ubiquitination limited to the $3^{\prime}$ UTR of target mRNAs? Are other RNA species (coding or non-coding, mature, or precursors) also ubiquitinated and what would be the effect on cancer biology? Which other factors are involved in the so far not well-understood mechanisms of mRNA ubiquitination and decay? 


\section{Concluding Remarks}

The ability of the MEX-3 proteins to negatively regulate the expression of tumor suppressor genes and their reported overexpression, after malignant transformation in several cases, highlights them as putative targets. Whether such intracellular MEX-3 proteins can be targeted by inhibitors or whether putative correlated cell surface markers could be identified by offering the opportunity for immunological therapies should be investigated in more detail.

Author Contributions: S.J.-B. and B.S. designed and wrote the review. A.S. assisted the bioinformatics analyses. All authors have read and agreed to the published version of the manuscript.

Funding: This work was funded by GIF (I-37-414.11-2016), the DFG (SE 581/22-1) and the Werner Jackstädt Foundation.

Acknowledgments: We would like to thank Nicole Ott for the excellent secretary help.

Conflicts of Interest: The authors declare no conflict of interest. The funders had no role in the design of the study; in the collection, analyses, or interpretation of data; in the writing of the manuscript, or in the decision to publish the results.

\section{Abbreviations}

$\begin{array}{ll}\text { ACC1 } & \text { acetyl-CoA-carboxylase-1 } \\ \text { APM } & \text { antigen processing machinery } \\ \text { C. elegans } & \text { Caenorhabditis elegans } \\ \text { CTL } & \text { cytotoxic T lymphocyte } \\ \text { EMT } & \begin{array}{l}\text { epithelial mesenchymal transition } \\ \text { ER }\end{array} \\ \text { endoplasmic reticulum } \\ \text { FASN } & \text { fatty acid synthase } \\ \text { HBV } & \text { hepatitis B virus } \\ \text { HLA } & \text { human leukocyte antigen } \\ \text { hnRNP } & \text { heterogeneous nuclear ribonucleoprotein } \\ \text { HOTAIR } & \text { HOX antisense intergenic RNA } \\ \text { IFN } & \text { interferon } \\ \text { KH } & \text { K-homology } \\ \text { MEX-3 } & \text { mex-3 RNA-binding family member } \\ \text { MHC } & \text { major histocompatibility complex } \\ \text { MHC-I } & \text { MHC class I } \\ \text { miRNA } & \text { microRNA } \\ \text { OS } & \text { overall survival } \\ \text { PD-1 } & \text { programed death receptor 1 } \\ \text { RBD } & \text { RNA-binding domain } \\ \text { RBP } & \text { RNA-binding protein } \\ \text { RUNX3 } & \text { runt-related transcription factor 3 } \\ \text { SREBP1 } & \text { sterol regulatory element-binding protein 1 } \\ \text { TCGA } & \text { The Tumor Cancer Genome Atlas } \\ \text { UTR } & \text { untranslated region } \\ & \end{array}$

\section{References}

1. Castello, A.; Fischer, B.; Frese, C.K.; Horos, R.; Alleaume, A.M.; Foehr, S.; Curk, T.; Krijgsveld, J.; Hentze, M.W. Comprehensive Identification of RNA-Binding Domains in Human Cells. Mol. Cell 2016, 63, 696-710. [CrossRef] [PubMed]

2. Hentze, M.W.; Castello, A.; Schwarzl, T.; Preiss, T. A brave new world of RNA-binding proteins. Nat. Rev. Mol. Cell Biol. 2018, 19, 327-341. [CrossRef]

3. Clery, A.; Blatter, M.; Allain, F.H. RNA recognition motifs: Boring? Not quite. Curr. Opin Struct Biol. 2008, 18, 290-298. [CrossRef] [PubMed]

4. Valverde, R.; Edwards, L.; Regan, L. Structure and function of KH domains. FEBS J. 2008, 275, $2712-2726$. [CrossRef] 
5. Linder, P.; Jankowsky, E. From unwinding to clamping-The DEAD box RNA helicase family. Nat. Rev. Mol. Cell Biol. 2011, 12, 505-516. [CrossRef] [PubMed]

6. Zheng, J.; Zhang, X.; Zhao, X.; Tong, X.; Hong, X.; Xie, J.; Liu, S. Deep-RBPPred: Predicting RNA binding proteins in the proteome scale based on deep learning. Sci. Rep. 2018, 8, 15264. [CrossRef] [PubMed]

7. Pereira, B.; Billaud, M.; Almeida, R. RNA-Binding Proteins in Cancer: Old Players and New Actors. Trends Cancer 2017, 3, 506-528. [CrossRef]

8. Buchet-Poyau, K.; Courchet, J.; Le Hir, H.; Seraphin, B.; Scoazec, J.Y.; Duret, L.; Domon-Dell, C.; Freund, J.N.; Billaud, M. Identification and characterization of human Mex-3 proteins, a novel family of evolutionarily conserved RNA-binding proteins differentially localized to processing bodies. Nucleic Acids Res. 2007, 35, 1289-1300. [CrossRef]

9. Cano, F.; Bye, H.; Duncan, L.M.; Buchet-Poyau, K.; Billaud, M.; Wills, M.R.; Lehner, P.J. The RNA-binding E3 ubiquitin ligase MEX-3C links ubiquitination with MHC-I mRNA degradation. EMBO J. 2012, 31, 3596-3606. [CrossRef]

10. Bufalieri, F.; Caimano, M.; Lospinoso Severini, L.; Basili, I.; Paglia, F.; Sampirisi, L.; Loricchio, E.; Petroni, M.; Canettieri, G.; Santoro, A.; et al. The RNA-Binding Ubiquitin Ligase MEX3A Affects Glioblastoma Tumorigenesis by Inducing Ubiquitylation and Degradation of RIG-I. Cancers 2020, 12, 321. [CrossRef]

11. Kuniyoshi, K.; Takeuchi, O.; Pandey, S.; Satoh, T.; Iwasaki, H.; Akira, S.; Kawai, T. Pivotal role of RNA-binding E3 ubiquitin ligase MEX3C in RIG-I-mediated antiviral innate immunity. Proc. Natl. Acad. Sci. USA 2014, 111, 5646-5651. [CrossRef]

12. Cano, F.; Rapiteanu, R.; Sebastiaan Winkler, G.; Lehner, P.J. A non-proteolytic role for ubiquitin in deadenylation of MHC-I mRNA by the RNA-binding E3-ligase MEX-3C. Nat. Commun. 2015, 6, 8670. [CrossRef] [PubMed]

13. Draper, B.W.; Mello, C.C.; Bowerman, B.; Hardin, J.; Priess, J.R. MEX-3 is a KH domain protein that regulates blastomere identity in early C. elegans embryos. Cell 1996, 87, 205-216. [CrossRef]

14. Fire, A.; Xu, S.; Montgomery, M.K.; Kostas, S.A.; Driver, S.E.; Mello, C.C. Potent and specific genetic interference by double-stranded RNA in Caenorhabditis elegans. Nature 1998, 391, 806-811. [CrossRef]

15. Ariz, M.; Mainpal, R.; Subramaniam, K.C. elegans RNA-binding proteins PUF-8 and MEX-3 function redundantly to promote germline stem cell mitosis. Dev. Biol. 2009, 326, 295-304. [CrossRef]

16. Calin, G.A.; Sevignani, C.; Dumitru, C.D.; Hyslop, T.; Noch, E.; Yendamuri, S.; Shimizu, M.; Rattan, S.; Bullrich, F.; Negrini, M.; et al. Human microRNA genes are frequently located at fragile sites and genomic regions involved in cancers. Proc. Natl. Acad. Sci. USA 2004, 101, 2999-3004. [CrossRef]

17. Burrell, R.A.; McClelland, S.E.; Endesfelder, D.; Groth, P.; Weller, M.C.; Shaikh, N.; Domingo, E.; Kanu, N.; Dewhurst, S.M.; Gronroos, E.; et al. Replication stress links structural and numerical cancer chromosomal instability. Nature 2013, 494, 492-496. [CrossRef]

18. Medawar, P.B. Immunity to homologous grafted skin; the fate of skin homografts transplanted to the brain, to subcutaneous tissue, and to the anterior chamber of the eye. Br. J. Exp. Pathol. 1948, 29, 58-69.

19. Benhar, I.; London, A.; Schwartz, M. The privileged immunity of immune privileged organs: The case of the eye. Front. Immunol. 2012, 3, 296. [CrossRef]

20. Uhlen, M.; Fagerberg, L.; Hallstrom, B.M.; Lindskog, C.; Oksvold, P.; Mardinoglu, A.; Sivertsson, A.; Kampf, C.; Sjostedt, E.; Asplund, A.; et al. Proteomics. Tissue-based map of the human proteome. Science 2015, 347, 1260419. [CrossRef]

21. Thul, P.J.; Akesson, L.; Wiking, M.; Mahdessian, D.; Geladaki, A.; Ait Blal, H.; Alm, T.; Asplund, A.; Bjork, L.; Breckels, L.M.; et al. A subcellular map of the human proteome. Science 2017, 356. [CrossRef] [PubMed]

22. Ponten, F.; Jirstrom, K.; Uhlen, M. The Human Protein Atlas-a tool for pathology. J. Pathol. 2008, 216, $387-393$. [CrossRef]

23. Ruhl, R.; Rana, S.; Kelley, K.; Espinosa-Diez, C.; Hudson, C.; Lanciault, C.; Thomas, C.R., Jr.; Liana Tsikitis, V.; Anand, S. microRNA-451a regulates colorectal cancer proliferation in response to radiation. BMC Cancer 2018, 18, 517. [CrossRef] [PubMed]

24. Huang, Y.; Fang, C.; Shi, J.W.; Wen, Y.; Liu, D. Identification of hMex-3A and its effect on human bladder cancer cell proliferation. Oncotarget 2017, 8, 61215-61225. [CrossRef] [PubMed]

25. Jiang, H.; Zhang, X.; Luo, J.; Dong, C.; Xue, J.; Wei, W.; Chen, J.; Zhou, J.; Gao, Y.; Yang, C. Knockdown of hMex-3A by small RNA interference suppresses cell proliferation and migration in human gastric cancer cells. Mol. Med. Rep. 2012, 6, 575-580. [CrossRef] 
26. Shi, J.W.; Huang, Y. Mex3a expression and survival analysis of bladder urothelial carcinoma. Oncotarget 2017, 8, 54764-54774. [CrossRef]

27. Chatterji, P.; Rustgi, A.K. RNA Binding Proteins in Intestinal Epithelial Biology and Colorectal Cancer. Trends Mol. Med. 2018, 24, 490-506. [CrossRef]

28. Fernandez-Barral, A.; Costales-Carrera, A.; Buira, S.P.; Jung, P.; Ferrer-Mayorga, G.; Larriba, M.J.; Bustamante-Madrid, P.; Dominguez, O.; Real, F.X.; Guerra-Pastrian, L.; et al. Vitamin D differentially regulates colon stem cells in patient-derived normal and tumor organoids. FEBS J. 2020, 287, 53-72. [CrossRef]

29. Pereira, B.; Sousa, S.; Barros, R.; Carreto, L.; Oliveira, P.; Oliveira, C.; Chartier, N.T.; Plateroti, M.; Rouault, J.P.; Freund, J.N.; et al. CDX2 regulation by the RNA-binding protein MEX3A: Impact on intestinal differentiation and stemness. Nucleic Acids Res. 2013, 41, 3986-3999. [CrossRef]

30. Oda, T.; Yamazumi, Y.; Hiroko, T.; Kamiya, A.; Kiriya, S.; Suyama, S.; Shiozaki-Sato, Y.; Akiyama, T. Mex-3B induces apoptosis by inhibiting miR-92a access to the Bim-3'UTR. Oncogene 2018, 37, 5233-5247. [CrossRef]

31. Yamazumi, Y.; Sasaki, O.; Imamura, M.; Oda, T.; Ohno, Y.; Shiozaki-Sato, Y.; Nagai, S.; Suyama, S.; Kamoshida, Y.; Funato, K.; et al. The RNA Binding Protein Mex-3B Is Required for IL-33 Induction in the Development of Allergic Airway Inflammation. Cell Rep. 2016, 16, 2456-2471. [CrossRef] [PubMed]

32. Yamazumi, Y.; Sasaki, O.; Suyama-Fuchino, S.; Kohu, K.; Kamoshida, Y.; Harada, H.; Fujio, K.; Oda, T.; Akiyama, T. The RNA-binding protein Mex-3B plays critical roles in the development of steroid-resistant neutrophilic airway inflammation. Biochem. Biophys. Res. Commun. 2019, 519, 220-226. [CrossRef] [PubMed]

33. Le Borgne, M.; Chartier, N.; Buchet-Poyau, K.; Destaing, O.; Faurobert, E.; Thibert, C.; Rouault, J.P.; Courchet, J.; Negre, D.; Bouvard, D.; et al. The RNA-binding protein Mex3b regulates the spatial organization of the Rap1 pathway. Development 2014, 141, 2096-2107. [CrossRef] [PubMed]

34. Xue, M.; Chen, L.Y.; Wang, W.J.; Su, T.T.; Shi, L.H.; Wang, L.; Zhang, W.; Si, J.M.; Wang, L.J.; Chen, S.J. HOTAIR induces the ubiquitination of Runx3 by interacting with Mex3b and enhances the invasion of gastric cancer cells. Gastric Cancer 2018, 21, 756-764. [CrossRef]

35. Huang, L.; Malu, S.; McKenzie, J.A.; Andrews, M.C.; Talukder, A.H.; Tieu, T.; Karpinets, T.; Haymaker, C.; Forget, M.A.; Williams, L.J.; et al. The RNA-binding Protein MEX3B Mediates Resistance to Cancer Immunotherapy by Downregulating HLA-A Expression. Clin. Cancer Res. 2018, 24, 3366-3376. [CrossRef]

36. Kalbasi, A.; Ribas, A. Antigen Presentation Keeps Trending in Immunotherapy Resistance. Clin. Cancer Res. 2018, 24, 3239-3241. [CrossRef]

37. Chao, H.; Deng, L.; Xu, F.; Yu, Z.; Xu, X.; Huang, J.; Zeng, T. MEX3C regulates lipid metabolism to promote bladder tumorigenesis through JNK pathway. Onco. Targets Ther. 2019, 12, 3285-3294. [CrossRef]

38. Zhang, J.; Zhou, Y.J.; Yu, Z.H.; Chen, A.X.; Yu, Y.; Wang, X.; Cao, X.C. Identification of core genes and clinical roles in pregnancy-associated breast cancer based on integrated analysis of different microarray profile datasets. Biosci. Rep. 2019, 39. [CrossRef]

39. Cano, F.; Lehner, P.J. A novel post-transcriptional role for ubiquitin in the differential regulation of MHC class I allotypes. Mol. Immunol. 2013, 55, 135-138. [CrossRef]

40. Yang, L.; Wang, C.; Li, F.; Zhang, J.; Nayab, A.; Wu, J.; Shi, Y.; Gong, Q. The human RNA-binding protein and E3 ligase MEX-3C binds the MEX-3-recognition element (MRE) motif with high affinity. J. Biol. Chem. 2017, 292, 16221-16234. [CrossRef]

41. Mougeot, J.L.; Bahrani-Mougeot, F.K.; Lockhart, P.B.; Brennan, M.T. Microarray analyses of oral punch biopsies from acute myeloid leukemia (AML) patients treated with chemotherapy. Oral Surg. Oral Med. Oral Pathol. Oral Radiol Endod. 2011, 112, 446-452. [CrossRef] [PubMed]

42. Schinke, E.N.; Bii, V.; Nalla, A.; Rae, D.T.; Tedrick, L.; Meadows, G.G.; Trobridge, G.D. A novel approach to identify driver genes involved in androgen-independent prostate cancer. Mol. Cancer 2014, 13, 120. [CrossRef]

43. Guzman, B.; Cormand, B.; Ribases, M.; Gonzalez-Nunez, D.; Botey, A.; Poch, E. Implication of chromosome 18 in hypertension by sibling pair and association analyses: Putative involvement of the RKHD2 gene. Hypertension 2006, 48, 883-891. [CrossRef]

44. Jiao, Y.; Bishop, C.E.; Lu, B. Mex3c regulates insulin-like growth factor 1 (IGF1) expression and promotes postnatal growth. Mol. Biol. Cell 2012, 23, 1404-1413. [CrossRef]

45. Okamoto, M.; Kouwaki, T.; Fukushima, Y.; Oshiumi, H. Regulation of RIG-I Activation by K63-Linked Polyubiquitination. Front. Immunol. 2017, 8, 1942. [CrossRef] 
46. Lu, P.; Li, H.; Li, N.; Singh, R.N.; Bishop, C.E.; Chen, X.; Lu, B. MEX3C interacts with adaptor-related protein complex 2 and involves in miR-451a exosomal sorting. PLoS ONE 2017, 12, e0185992. [CrossRef] [PubMed]

47. Han, C.; Jiao, Y.; Zhao, Q.; Lu, B. Mex3c mutation reduces adiposity partially through increasing physical activity. J. Endocrinol. 2014, 221, 457-468. [CrossRef] [PubMed]

48. Sagata, N.; Kato, T.A.; Kano, S.I.; Ohgidani, M.; Shimokawa, N.; Sato-Kasai, M.; Hayakawa, K.; Kuwano, N.; Wilson, A.M.; Ishizuka, K.; et al. Dysregulated gene expressions of MEX3D, FOS and BCL2 in human induced-neuronal (iN) cells from NF1 patients: A pilot study. Sci. Rep. 2017, 7, 13905. [CrossRef]

49. Courchet, J.; Buchet-Poyau, K.; Potemski, A.; Bres, A.; Jariel-Encontre, I.; Billaud, M. Interaction with 14-3-3 adaptors regulates the sorting of hMex-3B RNA-binding protein to distinct classes of RNA granules. J. Biol. Chem. 2008, 283, 32131-32142. [CrossRef]

50. Silipo, M.; Gautrey, H.; Tyson-Capper, A. Deregulation of splicing factors and breast cancer development. J. Mol. Cell Biol. 2015, 7, 388-401. [CrossRef]

51. Yang, D.; Jiao, Y.; Li, Y.; Fang, X. Clinical characteristics and prognostic value of MEX3A mRNA in liver cancer. Peer J. 2020, 8, e8252. [CrossRef]

52. Zeng, T.; Peng, L.; Chao, C.; Fu, B.; Wang, G.; Wang, Y.; Zhu, X. miR-451 inhibits invasion and proliferation of bladder cancer by regulating EMT. Int. J. Clin. Exp. Pathol. 2014, 7, 7653-7662.

53. Zhang, H.; Xing, Z.; Mani, S.K.; Bancel, B.; Durantel, D.; Zoulim, F.; Tran, E.J.; Merle, P.; Andrisani, O. RNA helicase DEAD box protein 5 regulates Polycomb repressive complex 2/Hox transcript antisense intergenic RNA function in hepatitis B virus infection and hepatocarcinogenesis. Hepatology 2016, 64, 1033-1048. [CrossRef]

54. Muthalagu, N.; Junttila, M.R.; Wiese, K.E.; Wolf, E.; Morton, J.; Bauer, B.; Evan, G.I.; Eilers, M.; Murphy, D.J. BIM is the primary mediator of MYC-induced apoptosis in multiple solid tissues. Cell Rep. 2014, 8, 1347-1353. [CrossRef] [PubMed]

55. Rodriguez, J.A. HLA-mediated tumor escape mechanisms that may impair immunotherapy clinical outcomes via T-cell activation. Oncol. Lett. 2017, 14, 4415-4427. [CrossRef] [PubMed]

56. Moududee, S.A.; Jiang, Y.; Gilbert, N.; Xie, G.; Xu, Z.; Wu, J.; Gong, Q.; Tang, Y.; Shi, Y. Structural and functional characterization of hMEX-3C Ring finger domain as an E3 ubiquitin ligase. Protein Sci. 2018, 27, 1661-1669. [CrossRef] [PubMed]

57. Yang, Y.; Wang, S.Y.; Huang, Z.F.; Zou, H.M.; Yan, B.R.; Luo, W.W.; Wang, Y.Y. The RNA-binding protein Mex3B is a coreceptor of Toll-like receptor 3 in innate antiviral response. Cell Res. 2016, 26, 288-303. [CrossRef] [PubMed]

58. Bukur, J.; Jasinski, S.; Seliger, B. The role of classical and non-classical HLA class I antigens in human tumors. Semin. Cancer Biol. 2012, 22, 350-358. [CrossRef] [PubMed]

59. Friedrich, M.; Jasinski-Bergner, S.; Lazaridou, M.F.; Subbarayan, K.; Massa, C.; Tretbar, S.; Mueller, A.; Handke, D.; Biehl, K.; Bukur, J.; et al. Tumor-induced escape mechanisms and their association with resistance to checkpoint inhibitor therapy. Cancer Immunol. Immunother. 2019, 68, 1689-1700. [CrossRef]

60. Holmstrom, M.O.; Cordua, S.; Skov, V.; Kjaer, L.; Pallisgaard, N.; Ellervik, C.; Hasselbalch, H.C.; Andersen, M.H. Evidence of immune elimination, immuno-editing and immune escape in patients with hematological cancer. Cancer Immunol. Immunother. 2020, 69, 315-324. [CrossRef]

61. Labani-Motlagh, A.; Ashja-Mahdavi, M.; Loskog, A. The Tumor Microenvironment: A Milieu Hindering and Obstructing Antitumor Immune Responses. Front. Immunol. 2020, 11, 940. [CrossRef] [PubMed]

62. Guillaudeux, T.; Rodriguez, A.M.; Girr, M.; Mallet, V.; Ellis, S.A.; Sargent, I.L.; Fauchet, R.; Alsat, E.; Le Bouteiller, P. Methylation status and transcriptional expression of the MHC class I loci in human trophoblast cells from term placenta. J. Immunol. 1995, 154, 3283-3299. [PubMed]

63. Jasinski-Bergner, S.; Stoehr, C.; Bukur, J.; Massa, C.; Braun, J.; Huttelmaier, S.; Spath, V.; Wartenberg, R.; Legal, W.; Taubert, H.; et al. Clinical relevance of miR-mediated HLA-G regulation and the associated immune cell infiltration in renal cell carcinoma. Oncoimmunology 2015, 4, e1008805. [CrossRef] [PubMed]

(C) 2020 by the authors. Licensee MDPI, Basel, Switzerland. This article is an open access article distributed under the terms and conditions of the Creative Commons Attribution (CC BY) license (http://creativecommons.org/licenses/by/4.0/). 